This is the accepted version of the following article:

Mauriz E., García-Fernández M.C., Lechuga L.M.. Towards the design of universal immunosurfaces for SPR-based assays: A review. TrAC - Trends in Analytical Chemistry, (2016). 79. : 191 - . 10.1016/j.trac. 2016.02.006,

which has been published in final form at https://dx.doi.org/10.1016/j.trac.2016.02.006 @ https://dx. doi.org/10.1016/j.trac. 2016.02.006. This manuscript version is made available under the CC-BY-NC-ND 4.0 license http: // creativecommons. org/licenses/by-nc-nd/4.0/ 


\section{Manuscript details}

Manuscript number

Title

Article type

Abstract

Keywords
TRAC_2015_224

Towards the design of universal

immunosurfaces for SPR-based assays:

a review

Review Article

Surface biofunctionalization, including chemical activation and attachment

of the bioreceptor, is an essential step to provide reliable detection of biomolecular binding events monitored by Surface Plasmon Resonance $(\mathrm{SPR})$, the most employed optical biosensor, and other biosensor techniques. Recent progress in the area of immobilization procedures are aimed at producing reproducible interfacial surfaces that enable the sensitive and specific recognition of the analyte. Antibodies are still the most employed bioreceptors for SPR assays. A wide range of strategies have been proposed to maximize the SPR immunosensor performance by controlling the stability and orientation of the immobilized antibody. This article reviews the most recent advancements in random and oriented antibody immobilization approaches for SPR biosensing applications, with a special focus on the research

that have been done to find universal linkers, which can allow the use of the same functionalized surface for different applications.

SPR; biofunctionalizacion; antibody immobilization; special immunosurfaces 
Corresponding Author

Order of Authors

Suggested reviewers
Elba Mauriz

Elba Mauriz, María Camino García-Fernández, LAURA LECHUGA

Peter Hansen, M.-Pilar MARCO

\section{Submission files included in this PDF}

File Type

Manuscript

Figure

Figure

Figure

Figure

Table

Cover Letter

Highlights

Response to reviewers
File Name

Towards the design of universal immunosurfaces revised.

Figlrevised.docx

Fig.2.docx

Fig.3.docx

Fig.4.docx

Table 1. docx

covering letter.docx

highligts.docx

Responses to reviewer.docx

To view all the submission files, including those not included in the PDF, click on the manuscript title on your EVISE Homepage, then click 'Download zip file'. 


\title{
Towards the design of universal immunosurfaces for SPR-based assays: a review
}

\author{
E. Mauriz ${ }^{1, *}$, M.C. García- Fernández ${ }^{1}$ and L.M. Lechuga ${ }^{2}$ \\ ${ }^{1}$ Institute of Food Science and Technology (ICTAL), University of León, 24007 León, Spain. \\ e-mail: elba.mauriz@unileon.es \\ ${ }^{2}$ Nanobiosensors and Bioanalytical Applications Group. Catalan Institute of Nanoscience and \\ Nanotechnology (ICN2), CSIC, The Barcelona Institute of Science and Technology and CIBER-BBN, \\ Campus UAB, Ed-ICN2, 08193 Bellaterra, Barcelona, Spain.
}

\begin{abstract}
Surface biofunctionalization, including chemical activation and attachment of the bioreceptor, is an essential step to provide reliable detection of biomolecular binding events monitored by Surface Plasmon Resonance (SPR), the most employed optical biosensor, and other biosensor techniques. Recent progress in the area of immobilization procedures are aimed at producing reproducible interfacial surfaces that enable the sensitive and specific recognition of the analyte. Antibodies are still the most employed bioreceptors for SPR assays. A wide range of strategies have been proposed to maximize the SPR immunosensor performance by controlling the stability and orientation of the immobilized antibody. This article reviews the most recent advancements in random and oriented antibody immobilization approaches for SPR biosensing applications, with a special focus on the research that have been done to find universal linkers, which can allow the use of the same functionalized surface for different applications.
\end{abstract}

Keywords: SPR; biofunctionalization; antibody immobilization; special immunosurfaces

\section{Introduction}

The interest on Surface Plasmon Resonance (SPR) biosensor as a label-free tool for monitoring binding events in real time has been growing exponentially since the first publications expanding to clinical, environmental and food analysis applications [1-2]. Although SPR technology primarily focused on the improvement of the design and the miniaturization of the technological platforms [3], the feasibility of high performance SPR devices relies mostly on the correct incorporation and functionalization of the biological receptor recognition layer [1].

SPR biosensors commonly use antibodies as bioreceptors to recognize its complementary target. Although recent progress in biotechnology have led to the design of new recognition molecules as aptamers or imprinted polymers [4], theoretically able to replace antibodies, antibody-based assays are still the first choice for studying biomolecular interactions due to their superior performance. The production of antibodies can be directed against a large variety of molecules ranging from low to high 
molecular weight, as pesticides, hormones drugs and intact cells. Antibody production can be dedicated and expensive but the excellent properties of antibodies like affinity, selectivity and stability make immunoassays one of the most robust molecular biorecognition systems.

The selection of the immunoassay format frequently relies upon the nature and characteristics of the analyte which has to be determined. In a typical enzyme-linked immunosorbent assay (ELISAs) antibodies need to be labeled in order to obtain a detectable signal, whilst immunosensors as SPR allow direct determinations in real-time without the need of labels or additional steps [5]. Monitoring of immunoresponses by SPR biosensor can be obtained by using either the antigen or the antibody as ligands. For analytes with a molecular weight over $1000 \mathrm{Da}$, the use of antibodies as ligands is preferred so that the antibody immobilized onto the sensor surface may recognize its complementary antigen in a simple, fast and direct manner.

A number of immobilization models have been reported for the achievement of maximum immunosensor consistencies while preserving the biological activity of immobilized antibodies. The immunosurface stability is crucial since it prevents antibody denaturation and non-specific binding during the immunointeraction. The formation of well-ordered interfaces without damage of the immobilized antibodies is also an essential aspect for the achievement of reliable and sensitive biosensor platforms. The search for a universal immobilization method is still beyond our reach and many new immobilization techniques have been studied during the last years to achieve this goal. Figure 1 shows common and recent developments of surface biofunctionalization strategies.

Immobilization designs can exploit random or orientated formats in order to obtain the maximal functionality by enhancing the immunosensor capacity and/or the orientation of the antibody binding sites. Discussion on random and orientated antibody immobilization strategies has been addressed in some studies [6]. In general, random immobilization formats succeed in achieving higher surface coverages while strategies based on the orientation of antibodies provide better sensitivities for analyte detection. Random orientation of antibodies can be affected by steric hindrance and non-specific protein adsorption, resulting in antibody inactivation and lowest antigen binding capacity [7]. As a consequence, the oriented immobilization of antibodies, from sitedirecting methods to protein-binding proteins, is preferable since it affords chemical stability and optimal availability of the functional groups. The analytical performance between several random and oriented immobilization strategies is compared in Table 1.

The concern on the value of selecting the appropriate immobilization method for measuring antigen-antibody interactions [8] is demonstrated by the number of publications released every year. This review focuses on the recent advances of SPR immobilization strategies for immunoanalytical formats. In particular, we concentrate on the current trends based on the combination of traditional and novel biotechnological 
alternatives, like fusion proteins, polymer brushes and intact-fragmented antibodies, recently developed for the design of universal interfaces. Special attention has been paid to the functionalization of SPR biosensor surfaces with major applications in clinical diagnostics and real-time analysis.

\section{Antibody immobilization formats}

The classification of strategies for the immobilization of antibodies onto both unmodified and previously functionalized gold substrates is difficult due to the diversity of activation processes and the singularity of each recognition event. The following allocation refers to both, the method in which the antibody is linked to the sensor surface and the specific characteristics of the immunological interaction.

\subsection{Adsorption}

Direct adsorption onto gold surfaces by electrostatic forces has been the most employed antibody immobilization approach for decades. This method is simple and easy to perform. However, physical adsorption is an uncontrolled and non-specific process that may cause the inactivation and denaturation of immobilized antibodies. Consequently, the stability and the reproducibility of the assay decay.

During last years, some studies have reported the efficiency of different immobilization strategies by comparing physical adsorption with covalent coupling, specific adsorption via biotin orientation [9] or carbon nanotubes [10]. In spite of its clear disadvantages, physical adsorption in SPR sensors has been recently applied in clinical diagnostics for the detection of the tuberculosis antigen CFP 10 and the human fetuin A biomarker [11, 12]. Nevertheless, non-specific adsorption of antibodies on SPR sensor surfaces has proved to be the least sensitive and reliable immobilization method due to the conformational changes, steric hindrance and inappropriate orientation caused by the direct contact of antibodies with the metal surface.

\subsection{Covalent coupling by Self-assembled monolayers}

Covalent binding of antibodies to previously chemically modified substrates is the immobilization format most commonly employed for monitoring antigen-antibody interactions.

In particular, self-assembled monolayers (SAMs) of alkanethiolates are suitable for the immobilization of a wide variety of biological molecules. The antibody attachment through SAMs provides stable and ordered layers that reduce non-specific adsorptions [7].The formation of SAMs is simple and reproducible. Afterwards, the antibody is covalently cross-linked to the SAM. Gold thiol monolayers typically consist of alkyl 
thiol chains of 11 to 16 carbons that allow the antibody coupling to a chemically activated surface by using a mixture of $N$ hydroxysuccinimide (NHS) and 1-ethyl-3(-3dimethyl-aminopropyl) carbodiimide hydrochloride (EDC). In the reaction, EDC converts the carboxylic acid of the alkanethiol into a reactive intermediate $(\mathrm{N}$ hydroxysuccinimide ester), which is capable of attaching covalently the amine groups of the antibody. Due to its versatility, SAMs have been successfully employed in numerous bioanalytical applications ranging from cancer biomarkers detection (carcinoembriogenic antigen) [13] to on-line determinations of cell suspensions [14].

The search for robust and reliable immobilization protocols introduced variations to the common alkanethiolated SAMs technique. One common approach is the use of mixed layers of thiols. [15]. Mixed thiols SAMs take advantage of the difference in chain length to enhance the orientation of the immobilized antibodies while minimizing nonspecific adsorption. The formation of mixed SAMs typically includes one functionalized alkanethiolate with a carboxylic acid ending group at a low mole fraction and a non-functionalized thiolate of lower chain length at a high mole fraction [7]. The combined presence of both thiol types reduces steric hindrance by providing the appropriate concentration of functional groups [15].

Last trends in SAM based-immobilization models employ oligo- or poly-ethylene glycols (OEG or PEG) as spacers to enhance the assay sensitivity [16]. The functionalization of gold substrates based on polythiols, PEG and thiol-peptides [17] exploits the linkage between amine and thioacetal groups to form stable monolayers. In particular, PEG SAMs prevent nonspecific adsorption of proteins due to their antifouling capacity to overcome undesirable steric effects [18]. Their flexibility and hydrophilic properties generates the appropriate environment to avoid non-specific adsorption by both the compression and the presence of water molecules around PEG chains. Several variations of this model like the reaction of alkyl or polyoxyethylene chains with either silane or NHS groups have also been used for the covalent immobilization of antibodies. Likewise, the assemblage of peptide linkers [19] to SAMs and the application of dendrimer technology to the fabrication of nano-scale SPR sensor chips are other interesting approaches to improve the antibody orientation on SPR platforms. Specifically, dendrimer macromolecules consisting of a tridimensional architecture of hyperbranched polymers have been successfully applied to the design of nanohybrid Ag/Au structures [20]. In the same way, the potential of dendrimers as detecting agents has been exploited for the construction of conjugated systems with application in clinical diagnosis of allergy processes [21].

Finally, covalent attachment of antibodies by self-assembly technology has been associated with other immobilization techniques in order to obtain more feasible and reliable methods for the functionalization of gold substrates. Most of them compare the efficiency in terms of coverage and sensitivity with other strategies. For instance, SAM technology has been used in combination with specific adsorption by avidin-biotin binding [9, 22] (see Fig.2), poly-brushes [23] or protein binding proteins [24, 25]. Numerous examples of this type of SAM-based immunosensors have been published over the last few years. As shown in Table 1, better sensitivity and selectivity values are 
obtained for SAMs involving oriented immobilization formats and non-fouling biosurface designs. The combined use of oriented and non-fouling surfaces may enhance both antibody binding capacity and availability. Further information is given in the respective sections. Further information is given in the respective sections.

\subsection{Oriented immobilization by antibody binding proteins}

Functionalization of immunosurfaces via Protein A and Protein G binding is a common strategy to achieve site-oriented immobilization of antibodies. It consists primarily of an antibody binding protein coated surface that selectively captures the Fc region of antibodies leaving Fab bioactive sites free for the antigen specific interaction. Since Protein A and G contain 4-5 and 2-3 IgG binding domains respectively, antibodies can be properly orientated without the need of prior alteration and regardless the protein orientation. The result is a stable and sterically accessible immunosurface that preserve the antibody ability to recognize specifically its complementary target.

Antibody binding proteins are generally attached to gold-coated surfaces via thiolated SAMs or Dextran-Hydrogel coupling. Alternatives to traditional linking layers may involve protein modifications that provide reliable environments for SPR monitoring. For instance, Protein G can be chemically and genetically engineered [26, 27] to contain thiolate or cysteine residues. The addition of these groups contributes to the enhancement of immobilized antibodies with regard to non-chemically modified Protein $\mathrm{G}$ layers [28]. For instance, amine groups from lysine residues in protein $\mathrm{G}$ can be converted to thiol groups with 2-iminothiolane leading to the direct formation of a selfassembled protein $G$ layer and the subsequent attachment of antibodies through their nonantigenic regions. Similarly, Protein G bound to magnetic particles has been used with this aim to improve antibody orientation [29].

On the other hand, Protein A has been employed to construct complex bionanostructures by being assembled to gold binding proteins [30, 31] and biotin tags [32]. These procedures result in the formation of well-ordered layers that increase the accessibility of antigens to the antibodies binding sites avoiding undesirable effects of steric hindrance.

Another interesting approach is the autodisplay technology. This method has been broadly used in recent years to express the Z-domains of protein A with IgG binding activity as a fusion protein at the outer membrane of Escherichia coli and Staphilococcus aureus. The assay sensitivity can be improved by the controlled orientation of the Z domains [33]. Recently, E.coli cells with autodisplayed Z domains have also been associated with magnetic beads [34], nanocapsules [35] and chemically activated parylene films [36]. The increasing number of SPR studies on autodisplaying of Protein A, Z domains suggests that this trend may be interested to construct more stable and sensitive antibody-based analytical platforms. 


\subsection{Biotin-avidin specific adsorption}

The immobilization of antibodies via biotin-avidin coupling is a common choice to control the effect of receptor orientation in immunosurfaces. The biotin-avidin system provides high stability and physico-chemical resistance to the immobilized antibodies. Biotin can be bound to a wide range of macromolecules (proteins, peptides, oligonucleotides and antibodies) while maintaining its binding affinity towards avidin or avidin-related molecules such as streptavidin or less frequent concanavalin, neutravidin and catavidin [37-39]. Taking advantage of its four binding sites, streptavidin form a layer over a biotynilated surface with capacity to capture more efficiently the biotynilated antibody. The biotin-streptavidin binding can be easily disrupted by regeneration solutions allowing the repeated use of the same biotynilated surface. However, one meaningful limitation is the need of modifying chemically the biotynilated antibody thus increasing both the time and the cost of the analysis.

The search for original analytical developments has led to the use of combined biotinstreptavidin immobilization approaches. SPR more striking designs include the use of polymers for the construction of copolymer films of polypyrrole layers in the functionalization of single-chain antibodies and the development of biotin tagged glycopolymers for antibodies detection [40, 41].

The capacity of biotin-avidin complexes to orientate antibodies has been exploited in combination with non-specific adsorption or SAM-based covalent coupling to compare the efficiency of the immobilization process. Additionally, several new applications involving Protein G layer surfaces [42], biotin tagged aptamers [4] and single domain antibodies random- and site-specifically biotynilated have been tested to assess the sensitivity of different immobilization methods [38]. Other singular approaches include the assembly of biotynilated Protein A/G and Fc antibody fragments [32].

\subsection{D surfaces: Polymer supports}

The functionalization of the gold SPR sensor via polymers provides a versatile and heterogeneous 3D matrix for the entrapment of antibodies by adsorption, diffusion or covalent coupling. The antibody is immobilized in a controlled environment that assures its binding capacity and recognition properties under non-denaturing conditions.

Polymer-based platforms have been traditionally used in SPR biosensing, especially through Biacore CM5 dextran-hydrogel sensor chips. Dextran-based hydrogels are a common alternative to the covalent attachment of biomolecules. The main difference between dextran and thiolated SAMs is the concentration of immobilized ligands. The special conformation of dextran based-layers provides multiple binding sites permitting a high density of immobilized receptors. On the other hand, SAMs attain ultrathin layers that offer better control over the recognition capacity of the functional groups. Although both methods fail in offering optimal control for the oriented immobilization of 
molecules, thiolated SAM technology supplies much more ordered structures than hydrogels due to its flexibility and capacity to orientate the immobilized antibody in size and functionality while dextran hydrogels provide larger immobilization interfacial matrices [37]. In particular, carboxymethyl dextrans produce thicker functionalized layers $(100 \mathrm{nM})[43]$ that enable the covalent binding of the positively charged amine groups of antibodies to the ending carboxylic groups of the dextran, previously activated by a carbodiimide bonding.

Chemical variations to dextran hydrogels have been reported in recent years in order to obtain more efficient 3D networks. Among polymer supports currently available, the use of glycopolymer based on polyacrilamide hydrophobic compounds [44] have played a significant role as multi-dimensional surface matrices. For instance, methyl acrylamide polymers have been used in sandwich assays to detect Human IgG in combination with colloidal gold [45]. The spaced glycopolymer microarray showed enhanced lectin (Arachis hypogaea) binding compared to a non-spaced one [46].

Furthermore, the number of studies involving parylene coating has increased significantly over the last years. The construction of parylene films consists on the deposition of poly (p-xylylene) polymers by chemical vapor on SPR sensor chips. The efficiency of parylene polymers for improving the capture of antibodies has been proved to be 20 fold higher than 2D glass surfaces [47]. The detection range and sensitivity of several SPR applications based on parylene $\mathrm{H}$ with formyl groups is superior to other immobilization formats [48]. The autodisplaying technology of $\mathrm{Z}$ domains has been successfully used in combination with parylene $\mathrm{H}$ coating on medical diagnosis of inflammatory diseases. Likewise, covalent attachment of biomolecules has also been tested by the incorporation of primary amine groups on a parylene A film used as a linker layer and the coating of SPR sensor chips with hydrophilic carboxylic terminated polymer matrices [43]. A variation of polymer surfaces for immunosensing applications are copolymers of polypyrrole propilic acid films [49]. Electropolymerized copolymers of polypyrrole provide relevant information on the efficiency of SPR and electrochemical analysis of immunosensing events and the characterization of redox activity for detecting specific associations. The search for low-fouling substrates that diminish non-specific adsorptions has triggered the development of polymer brushes of (poly(2-hydroxyethyl methacrylate) (poly (HEMA)) and poly[oligo(ethylene glycol) methacrylate-co-glycidyl methacrylate] (POEGMA-co-GMA)) as valuable tools for increasing the immobilization area of SPR sensor chips [50]. SPR applications based on poly-brushes exploit the non-fouling properties of these configurations to provide densely packed surfaces with minimal thickness in order to obtain most sensitive assays for clinical diagnosis and biological research [10, 23]. Zwiteronic carboxybetaine polymers have also emerged as low-fouling agents to functionalize SPR substrates enabling the detection of analytes in complex media such undiluted human blood plasma [51].

The use of calixarene, a well-known protein artificial receptor, as linker system to biofunctionalize SPR sensor surfaces has been recently addressed. The formation of 
calixarene crown ether monolayers allow the selectivity and reliability of SPR assays while resembling experimentally native conditions [52]. The most common calixarene commercial application, ProLinker ${ }^{\mathrm{TM}}$, has proved to be more efficient in orienting antibodies when compared with other immobilization strategies like protein G and SAM covalent attachment [53] (see Fig. 3). In like manner, site directed immobilization of antibodies through conducting polymer substrates of polyamic acid have also been investigated to achieve well-orientated immunosurfaces.

The combination with other immobilization formats have permitted the use of polymers as stabilizers of antibody fragments coated on colloidal gold nanoparticles [45]. Additionally, polymers can contribute to reduce non-specific binding by using molecular layers of Fab antibody fragments intercalated with non-ionic polymers or non-fouling polymers in combination with photoreactive crosslinkers.

Other immobilization approaches have reported polymer supports as chitosan composites of silver nanoplates [54], cellulose membranes [55] polyestirene substrates [56] and thiolated polymers [57] which have been also used as supports for the immobilization of antibodies.

\subsection{Fragmented antibodies}

Coupling strategies may involve antibody modifications [6-38] (see Fig.4). Particularly, antibodies can be chemically fragmented or genetically engineered to use only the Fab fragment containing the antigen-binding domain. The immobilization of antibody fragments provides the appropriate site-specific orientation of the antigen binding Fab domains while contributing to increase the accessibility for analytes and the antigenantibody binding capacity [58]. Antibody fragments obtained from intact antibodies by enzyme digestion and chemical reduction contain free sulfhydryl groups that can be employed for either their direct immobilization on the gold surface or their chemical cross-linking to a previously activated SPR sensor chip [59].

The immobilization via their native thiol groups have been traditionally reported for direct antibody coupling to the gold surface [6]. More recently the functionalization of gold nanoparticles with antibody fragments has been exploited to enhance the sensitivity of SPR-based assays [45, 59]. The activation of sensor chips by Au-S linkages assures appropriate steric conditions while reducing hindrance and producing a 20-fold rise of antibody binding capacity [8].

Other works describe the use of single chain variable (scFv) and Fab fragments engineered by recombinant antibody technology [38]. Most frequent applications of recombinant technology involve: antibody tagging of hystidine and cysteine residues introduced at the end of the antibody fragments [60] and fusion proteins obtained from the connection of the variable regions of the heavy and light chains with a short linker peptide. Both genetically-engineered antibody modifications are directed to the 
construction of a controlled-orientated antibody density onto the sensor surface. A singular usage of recombinant technology is the fabrication of bispecific antibodies to functionalize gold substrates. Bispecific antibodies consist of fragments of two different monoclonal antibodies that can recognize two different types of antigens. SPR applications include the simultaneous determination of inflammatory biomarkers [62].

The combination of Antibody fragments with other immobilization strategies have been investigated in several applications which include the avidin-streptavidin system [38], polymer modified-surfaces and protein binding proteins formats [32] as shown in Fig. 1.

\subsection{Gold coated nanoparticles and nano-surface modifications}

Gold nanoparticles are one of the most extended strategies to enhance the sensitivity of SPR-based assays. Physical and chemical properties of gold nanoparticles have been primarily exploited for the immobilization of antibodies. For instance, conjugates of antibody fragments and gold nanoparticles have been used to improve the functionality and stabilization of SPR assays solely [59] or in combination with intercalated polymers [45].

Recent applications involving novel antibody immobilization formats use gold-coated magnetic nanoparticles and nanocomposites of magnetic gold nanorods [9, 63]. Other approaches employ gold nanoparticle-antibody conjugates either for the characterization of the bioconjugation process or for the detection enhancement by incorporating graphene oxide layers to the functionalized surface area [64, 65].

A number of publications during last years also describe localized surface plasmon resonance properties of gold nanoparticles of all type of shapes and sizes for the improvement of plasmonic biosensors performance. Likewise, the use of nanosurface modifications such as multi- or single walled carbon nanotubes platforms [10], graphene or graphene oxide, nano-gratings, nano-patterned surfaces and nanohole arrays have also been considered to enhance the sensitivity of the SPR response [66].

\subsection{Other strategies}

Oher alternative immobilization methods as fusion proteins have been successfully applied to achieve reproducible immunodetection formats. Most frequent approaches are based on recombinant genetic techniques in order to obtain gold binding polypeptides (GBP) with the capacity of directly anchoring to gold surfaces [67]. Genetically engineered proteins have allowed the direct binding to the gold substrate by fusing to single chain fragmented antibodies. Fusion proteins of Protein A and concanavalin-Streptavidin formats have also been produced in Escherichia coli to provide effective antibody immobilization [30-31, 68]. 
An interesting approach is the application of DNA-directed antibody immobilization procedures that consist on the hybridization of single stranded DNA-antibody conjugates to complementary DNA sequences previously immobilized on the gold surface [69]. DNA-antibody hybrids are fabricated by chemical synthesis of oligonucleotides covalently coupled to specific antibodies directed against a target analyte. This method provides sensitive and flexible surfaces to construct protein receptor layers. Moreover, by using this immobilization approach SPR monitoring may also provide detection of molecular and cellular interaction events occurring at the sensor surface [70].

Other significant examples are the construction of SPR platforms based on aryl dizonium electrographting to achieve a significant improvement in antifouling coatings [71]. Pairwise antibody footprinting is also a relevant approach for the direct immobilization of antibodies to block the unoccupied immobilized anti-Fc to prevent non-specific antibody binding [72]. Distinct methods ranging from kinetic studies of antibodies immobilized into liposomes to straightforward antibody immobilization via immersion in dithiocarbamate solutions have been studied for the construction of rapid and direct immobilization methods [73, 74].

\section{Conclusions}

The increase of the number of applications which can be reached by SPR biosensors has triggered the search for versatile and reliable immobilization protocols. The investigation on novel immune receptor surfaces has growth in parallel with the progress of genetic engineering and the expansion of biomaterials science to produce stable biological supports. Among them, antibody-based bioreceptors systems lead the query of universal linkers for immunodetection assays.

In spite of the need for a general method, conventional antibody immobilization strategies seem to rely on the particular features of each assay system. One of the most controversial debates is the random versus orientated immobilization format. Investigation on the subject suggests significant benefits of oriented immobilization formats for improving assay selectivity. The construction of non-fouling receptor layers is also an interesting step in order to avoid non-specific adsorptions while preserving antibody properties. Comparison between immobilization strategies suggests that antibody orientation provides more sensitive detection assays whereas superior surface densities are obtained by random covalent immobilization formats.

Although a universal immobilization method has not yet figured out, advancements in biological interfaces may contribute to achieve better outcomes regardless the singularity of the assay format. Current immobilization formats take advantage of progress in chemically modified biosurfaces for the construction of high feasible bioreceptor layers. Furthermore studies on activity, thermodynamic and kinetic binding 
parameters may also provide a valuable background to improve the efficiency of SPR biosensor surfaces.

\section{Acknowledgements}

The nanoB2A is a consolidated research group (Grup de Recerca) of the Generalitat de Catalunya and has support from the Departament d'Universitats, Recerca i Societat de la Informació de la Generalitat de Catalunya (2014 SGR 624). ICN2 is the recipient of Grant SEV2013-0295 from the "Severo Ochoa Centers of Excellence" Program of Spanish MINECO.

\section{References}

[1] J. Homola, Chem. Rev. 108 (2008) 462.

[2] M.C. Estevez, M. Alvarez, L.M. Lechuga, Laser \& Photonics Reviews 6 (2012) 463.

[3] A. Abbas, M.J. Linman, Q. Cheng, Biosensors \& Bioelectronics 26 (2011) 1815.

[4] A. Henseleit, S. Schmieder, T. Bley, F. Sonntag, N. Schilling, P. Quenzel, N. Danz, U.Klotzbach, E. Boschke, Engineering In Life Sciences 11 (2011) 573.

[5] M. Piliarik, H. Vaisocherova, J. Homola, Methods in molecular biology (Clifton, N.J.) 503 (2009) 65.

[6] A. Kausaite-Minkstimiene, A. Ramanaviciene, J. Kirlyte, A. Ramanavicius, Analytical Chemistry 82 (2010) 6401.

[7] D.R. Shankaran, N. Miura, Journal Of Physics D-Applied Physics 40 (2007) 7187.

[8] Y. Jung, J.Y. Jeong, B.H. Chung, Analyst 133 (2008) 697.

[9] O. Torun, I. Hakki Boyaci, E. Temur, U. Tamer, Biosens Bioelectron 37 (2012) 53.

[10] W. Hu, Z. Lu, Y. Liu, C.M. Li, Langmuir 26 (2010) 8386.

[11] S.C. Hong, H. Chen, J. Lee, H.-K. Park, Y.S. Kim, H.-C. Shin, C.-M. Kim, T.J. Park, S.J. Lee, K. Koh, H.-J. Kim, C.L. Chang, J. Lee, Sensors And Actuators B-Chemical 156 (2011) 271.

[12] S.K.Vashist, E.M. Schneider, J.H. Luong, Analyst 139 (2014) 2237.

[13] Z. Altintas, Y. Uludag, Y. Gurbuz, I.E. Tothill, Talanta 86 (2011) 377.

[14] E. Mauriz, S. Carbajo-Pescador, R. Ordoñez, M. C. García-Fernández,J. L. Mauriz, L. M. Lechuga, J. González-Gallego Analyst 139 (2014) 1426.

[15] W.-C. Tsai, I.-C. Li, Sensors And Actuators B-Chemical 136 (2009) 8.

[16] H. Vaisocherova, W. Yang, Z. Zhang, Z. Cao, G. Cheng, M. Piliarik, J. Homola, S. Jiang, Analytical Chemistry 80 (2008) 7894.

[17] D. Kyprianou, A.R. Guerreiro, M. Nirschl, I. Chianella, S. Subrahmanyam, A.P.F. Turner, S. Piletsky, Biosensors \& Bioelectronics 25 (2010) 1049.

[18] J. Tsai Liu, C. J. Chen, T. Ikomac, T. Yoshiokac,

J. S. Cross , S-J Changa, J-Z Tsai , J. Tanakac Analytica Chimica Acta 703 (2011) 80.

[19] O.R. Bolduc, P. Lambert-Lanteigne, D.Y. Colin, S.S. Zhao, C. Proulx, D. Boeglin, W.D. Lubell, J.N. Pelletier, J. Fethiere, H. Ong, J.-F. Masson, Analyst 136 (2011) 3142.

[20] S. Roy, C.K. Dixit, G. Manickam, S. Daniels, C. McDonagh, Langmuir 29 (2013) 4430

[21] M. Soler, P. Mesa-Antunez, M.C. Estevez, A.J. Ruiz-Sanchez, M.A. Otte, B. Sepulveda, D. Collado, C. Mayorga, M.J. Torres, E. Perez-Inestrosa, L.M. Lechuga Biosens Bioelectron. 66 (2015) 115

[22] L. Roussille, G. Brotons, L. Ballut, G. Louarn, D. Ausserre, S. Ricard-Blum, Analytical And Bioanalytical Chemistry 401 (2011) 1601.

[23] C. Rodriguez-Emmenegger, O.A. Avramenko, E. Brynda, J. Skvor, A. Bologna Alles, BiosensBioelect26 (2011) 4545.

[24] S.K. Vashist, C.K. Dixit, B.D. MacCraith, R. O'Kennedy, Analyst 136 (2011) 4431.

[25] T.-H. Chou, C.-Y. Chuang, C.-M. Wu, Cytokine 51 (2010) 107.

[26] J.M. Fowler, M.C. Stuart, D.K.Y. Wong, Analytical Chemistry 79 (2007) 350.

[27] J.M. Lee, H.K. Park, Y. Jung, J.K. Kim, S.O. Jung, B.H. Chung, Analytical Chemistry 79 (2007) 2680. 
[28] Y. Jung, J.M. Lee, H. Jung, B.H. Chung, Analytical Chemistry 79 (2007) 6534.

[29] D. Garibo, K. Campbell, A. Casanova, P. de la Iglesia, M. Fernández-Tejedor, J. Diogène, C.T. Elliott, M. Campàs,Sensors and Actuators B 190 (2014) 822.

[30] S. Ko, T.J. Park, H.-S. Kim, J.-H. kim, Y.-J. Cho, Biosensors \& Bioelectronics 24 (2009) 2592.

[31] E. de Juan-Franco, A. Caruz, J.R. Pedrajas, L.M. Lechuga, Analyst 138 (2013) 2023.

[32] M.J.W. Ludden, X. Li, J. Greve, A. van Amerongen, M. Escalante, V. Subramaniam, D.N. Reinhoudt, J. Huskens, Journal Of The American Chemical Society 130 (2008) 6964.

[33] M. Park, J. Jose, J.-C. Pyun, Sensors And Actuators B-Chemical 154 (2011) 82.

[34] G. Yoo, M. Park, E.-H. Lee, J. Jose, J.-C. Pyun, Analytica Chimica Acta 707 (2011) 142.

[35] M. Iijima, H. Kadoya, S. Hatahira, S. Hiramatsu, G. Jung, A. Martin, J. Quinn, J. Jung, S.Y. Jeong, E.K. Choi, T. Arakawa, F. Hinako, M. Kusunoki, N. Yoshimoto, T. Niimi, K. Tanizawa, S.i. Kuroda, Biomaterials 32 (2011) 1455.

[36] E.-H. Lee, G. Yoo, J. Jose, M.-J. Kang, S.-M. Song, J.-C. Pyun, Biochip Journal 6 (2012) 221.

[37]G. Gupta, P.K. Singh, M. Boopathi, D.V. Kamboj, B. Singh, R. Vijayaraghavan, Thin Solid Films 519 (2010) 1171.

[38]S.A. Walper, P.A.B. Lee, E.R. Goldman, G.P. Anderson, Journal Of Immunological Methods 388 (2013) 68.

[39] E. de Juan-Franco, J.M. Rodríguez-Frade, M. Mellado,L.M. Lechuga, Talanta. 114(2013) 268.

[40] H.Q.A. Le, H. Sauriat-Dorizon, H. Korri-Youssoufi, Analytica Chimica Acta 674 (2010) 1.

[41] A. Alikhani, E.Y. Korchagina, A.A. Chinarev, N.V. Bovin, W.J. Federspiel, Journal Of Biomedical Materials Research Part B-Applied Biomaterials 91B (2009) 845.

[42] H.Y. Song, X. Zhou, J. Hobley, X. Su, Langmuir 28 (2012) 997.

[43] J.S. Mitchell, European Polymer Journal 47 (2011) 16.[44] V. Chegel, M.J. Whitcombe,

N.W. Turner, S.A. Piletsky, Biosensors \& Bioelectronics 24 (2009) 1270

[45] W.M. Albers, T. Munter, P. Laaksonen, I. Vikholm-Lundin, Journal Of Colloid And Interface Science 348 (2010) 1.

[46] S.N. Narla, X.-L. Sun, Lab On A Chip 12 (2012) 1656.

[47] P.T. Charles, E.R. Goldman, J.G. Rangasammy, C.L. Schauer, M.S. Chen, C.R. Taitt, Biosens Bioelectro 20 (2004) 753.

[48] H. Ko, E.-H. Lee, G.-Y. Lee, J. Kim, B.-J. Jeon, M.-H. Kim, J.-C. Pyun, Biosensors \& Bioelectronics 30 (2011) 56.

[49] H.Q.A. Lê, H. Sauriat-Dorizon, H. Korri-Youssoufi Analytica Chimica Acta 674 (2010) 1. [50] H. Vaisocherova, V. Sevcu, P. Adam, B. Spackova, K. Hegnerova, A.d.l.S. Pereira, C. Rodriguez-Emmenegger, T. Riedel, M. Houska, E. Brynda, J. Homola, Biosensors \& Bioelectronics 51 (2014) 150.

[51] N.D. Brault, A.D. White, A.D. Taylor, Q. Yu, S. Jiang, Analytical Chemistry 85 (2013) 1447.

[52] H. Chen, J. Lee, W.-S. Jo, M.-H. Jeong, K. Koh, Microchimica Acta 172 (2011) 171.

[53] M. Soler, M.- C. Estevez, M. Alvarez, M. A. Otte, B. Sepulveda, L. M. Lechuga, Sensors 14 (2014) 223.

[54] J. Zhang, Y. Sun, H. Zhang, B. Xu, H. Zhang, D. Song, Analytica Chimica Acta 769 (2013) 114.

[55] T. Miura, T. Horiuchi, Y. Iwasaki, M. Seyama, S. Camou, J.-i. Takahashi, T. Haga, Sensors And Actuators B-Chemical 173 (2012) 354.

[56] S. Auer, R.S. Lappalainen, H. Skottman, R. Suuronen, S. Narkilahti, I. Vikholm-Lundin, Journal Of Neuroscience Methods 186 (2010) 72. 
[57] D. Kyprianou, A.R. Guerreiro, I. Chianella, E.V. Piletska, S.A. Fowler, K. Karim, M.J. Whitcombe, A.P.F. Turner, S.A. Piletsky, Biosensors \& Bioelectronics 24 (2009) 1365.

[58] J. Baniukevic, J. Kirlyte, A. Ramanavicius, A. Ramanaviciene, Sensors And Actuators BChemical 189 (2013) 217.

[59] M. Wasowicz, M. Milner, D. Radecka, K. Grzelak, H. Radecka, Sensors 10 (2009) 5409

[60] J.E. Baio, F. Cheng, D.M. Ratner, P.S. Stayton, D.G. Castner, Journal Of Biomedical Materials Research Part A 97A (2011) 1.

[61] T. Ibii, M. Kaieda, S. Hatakeyama, H. Shiotsuka, H. Watanabe, M. Umetsu, I. Kumagai, T. Imamura, Analytical Chemistry 82 (2010) 4229.

[62] P. Kanakaraj, B. A. Puffer, X.-T. Yao, S. Kankanala, E. Boyd, R. R. Shah, G. Wang, D.Patel, R. Krishnamurthy, S. Kaithamana, R. G. Smith, D. W. LaFleur, C. F. Barbas, D.M. Hilbert, P. A. Kiener, V. V. Roschke, MAbs. 4 (2012) 4(5): 600.

[63] H. Zhang, Y. Sun, J. Wang, J. Zhang, H. Zhang, H. Zhou, D. Song, Biosensors \& Bioelectronics 34 (2012) 137.

[64] T. Springer, J. Homola, Analytical And Bioanalytical Chemistry 404 (2012) 2869.

[65] J. Zhang, Y. Sun, Q. Wu, H. Zhang, Y. Bai, D. Song, Analyst 138 (2013) 7175.

[66] F. Eftekhari, C. Escobedo, J. Ferreira, X. Duan, E.M. Girotto, A.G. Brolo, R. Gordon, D. Sinton, Analytical Chemistry 81 (2009) 4308.

[67] T.J. Park, S.J. Lee, D.-K. Kim, N.S. Heo, J.Y. Park, S.Y. Lee, Talanta 89 (2012) 246.

[68] N. Dassinger, D. Vornicescu, S. Merkl, M. Kehrel, E. Dayyoub, U. Bakowsky, M. Keusgen, Physica Status Solidi A-Applications And Materials Science 209 (2012) 832.

[69] J. Ladd, A.D. Taylor, M. Piliarik, J. Homola, S. Jiang, Analytical Chemistry 80 (2008) 4231.

[70] R. Bombera , L. Leroy,T. Livache,Y. Roupioz, Biosens Bioelectron 33 (2012) 10.

[71] Q. Zou, L.L.Kegel, K.S: Booksh, .Anal Chem. 87 (2015) 2488.

[72] V. Towne, Q. Zhao, M. Brown, A.C. Finnefrock, Journal Of Immunological Methods 388 (2013) 1.

[73] Y. Olguin, P. Villalobos, L.G. Carrascosa, M. Young, E. Valdez, L. Lechuga, R. Galindo, Analytical And Bioanalytical Chemistry 405 (2013) 1267.

[74] Y. Niu, A.I. Matos, L.M. Abrantes, A.S. Viana, G. Jin, Langmuir 28 (2012) 17718 
Fig. 1. Novel immobilization strategies based on combinations of common and recent developments of surface functionalization.

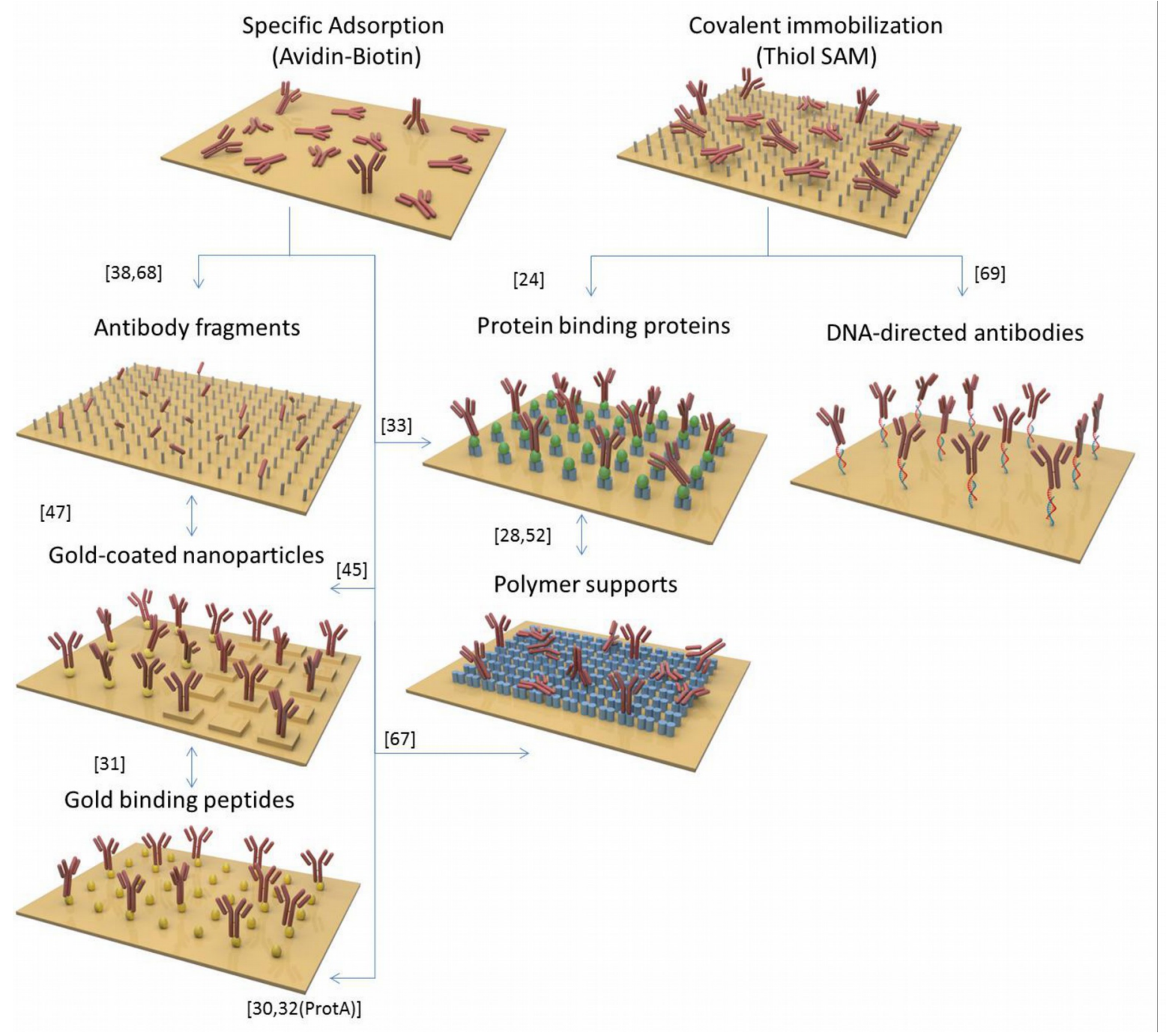


Fig. 2 (a) Sensorgrams obtained for covalent immobilization ofendostatin on a 1 mmol L-1 SAM-MHDA (99\% pure 16-MHDA) sensor chip (solid line), a control flow cell lacking endostatin (dashed groups by injection of EDC-NHS for $600 \mathrm{~s}$, injection of endostatin in $10 \mathrm{mmol} \mathrm{L}-1 \mathrm{maleate}$ buffer pH 6 (solid line) or of maleate buffer alone (dashed line) for $600 \mathrm{~s}$, injection of $1 \mathrm{~mol} \mathrm{~L}-1$ ethanolamine $\mathrm{pH} 8.5$ for $600 \mathrm{~s}$, two injections of HBS-P+for $60 \mathrm{~s}$ each (data not shown). All steps were performed at $5 \mu \mathrm{L} \mathrm{min}-1$ and sharp increases in the SPR signal were because of changes in refractive index. (b) Injection of a polyclonal anti-endostatin antibody (162.5 nmol L-1) over immobilized endostatin on different sensor chips at $30 \mu \mathrm{L}$ min-1 (after subtraction of the non-specific SPR signal measured on the control flow cell). The arrows indicate the beginning and the end of the IgG injection (Reprinted from [22] with permission from Springer).

a

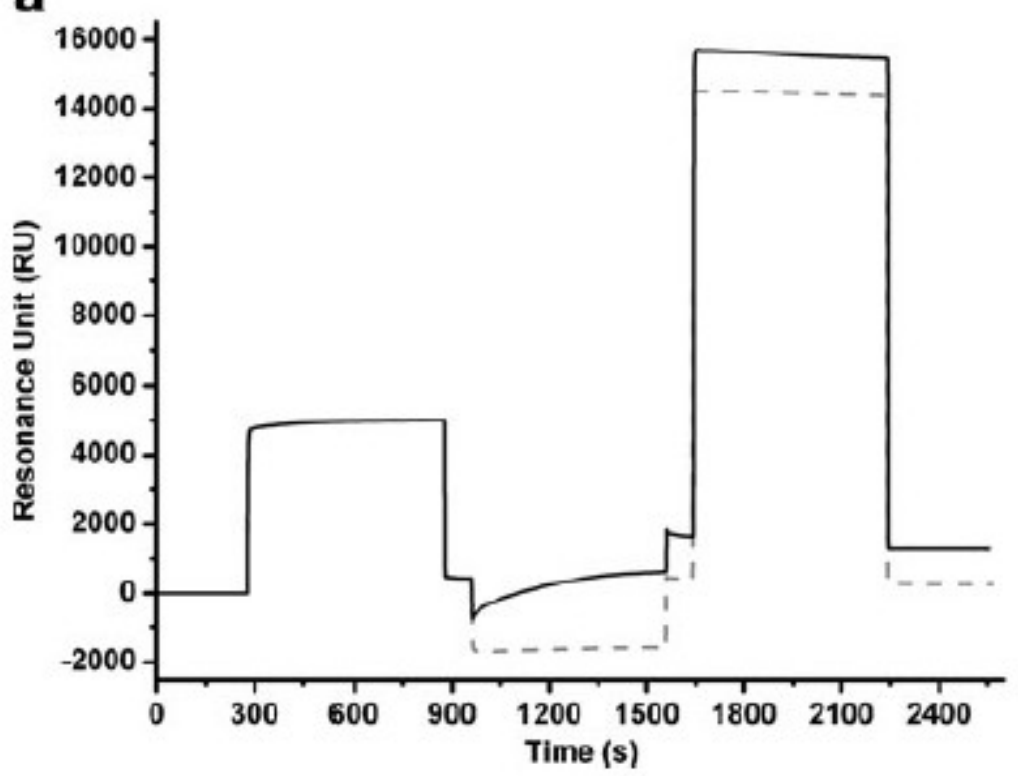

b

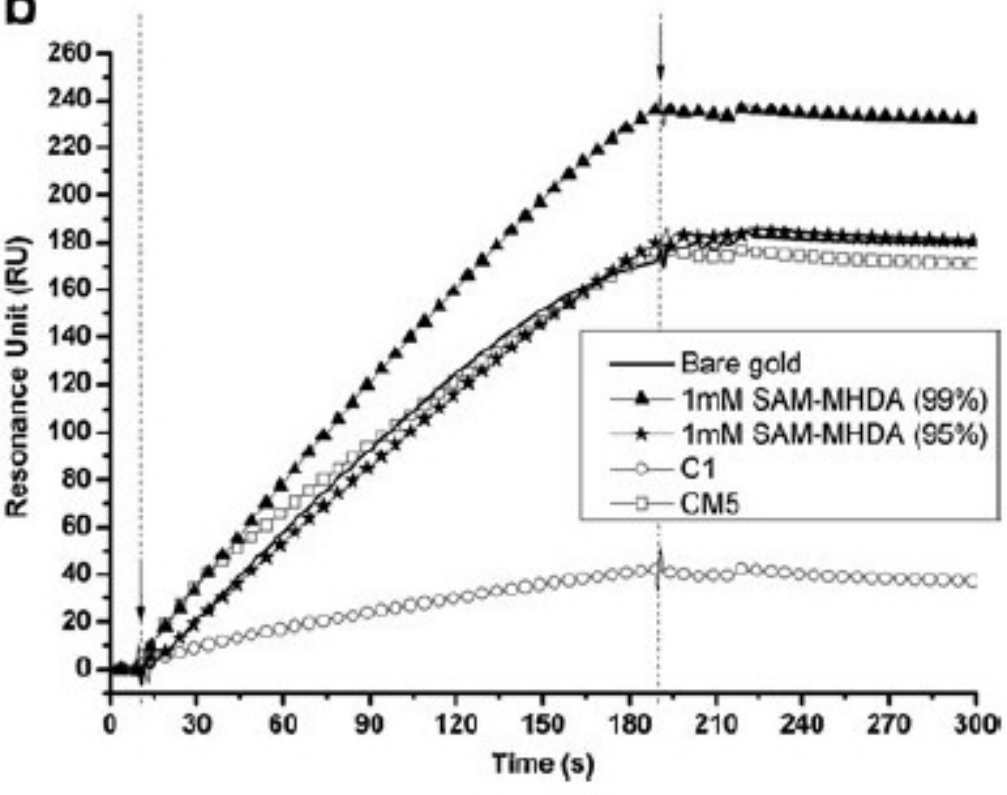


Fig. 3. (a) Comparison of antibody immobilizations at different antibody concentrations (5, 10, 20, 50, $100 \mu \mathrm{g} / \mathrm{mL})$ with different strategies. Grey: covalent strategy; Green: Protein G strategy ([Protein G] = $50 \mu \mathrm{g} / \mathrm{mL}$ ); Purple: ProLinker ${ }^{\mathrm{TM}}$ strategy; (b) Antigen detection performed with hCG/antihCG for covalent strategy (black), Protein G strategy (green) and ProLinker ${ }^{\mathrm{TM}}$ strategy (purple). Concentration of anti-hCG antibody was $10 \mu \mathrm{g} / \mathrm{mL}$ in all cases. Dashed lines represent adsorption of nonspecific proteins onto antibody functionalized surfaces for covalent strategy (black), Protein $G$ strategy (green) and ProLinker ${ }^{\mathrm{TM}}$ strategy (purple). Blue dotted line indicates additional control for the ProLinker ${ }^{\mathrm{TM}}$ strategy, based on the detection of hCG onto a nonspecific antibody $(10 \mu \mathrm{g} / \mathrm{mL})$ immobilized over ProLinker ${ }^{\mathrm{TM}}$ layer (same experimental conditions as with specific antibody). (Reprinted from [53] with permission from MDPI).

(a)

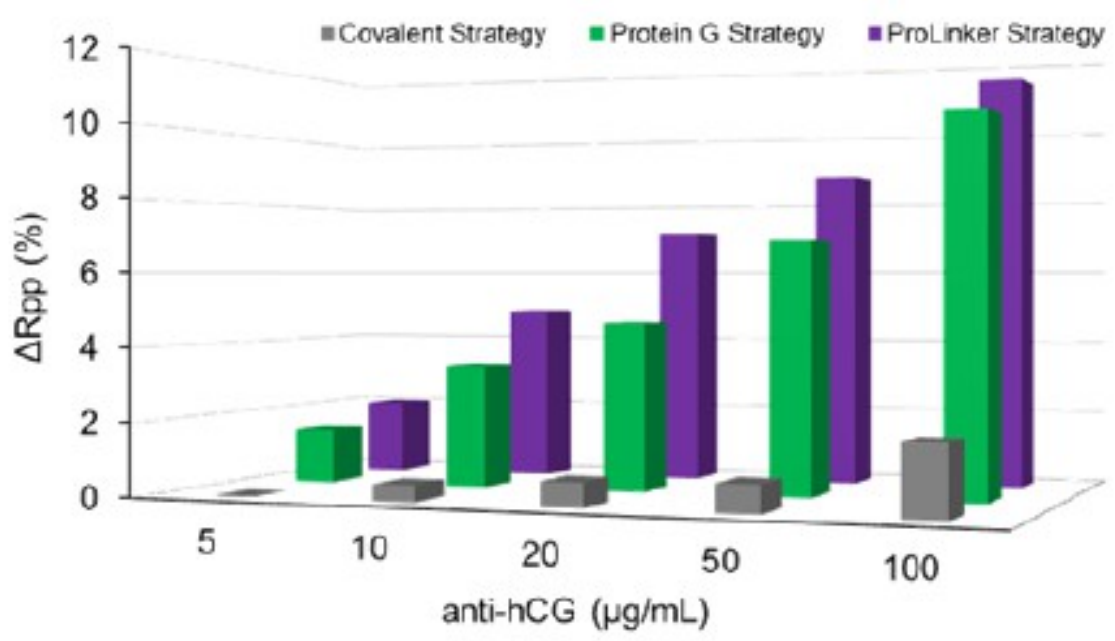

(b)

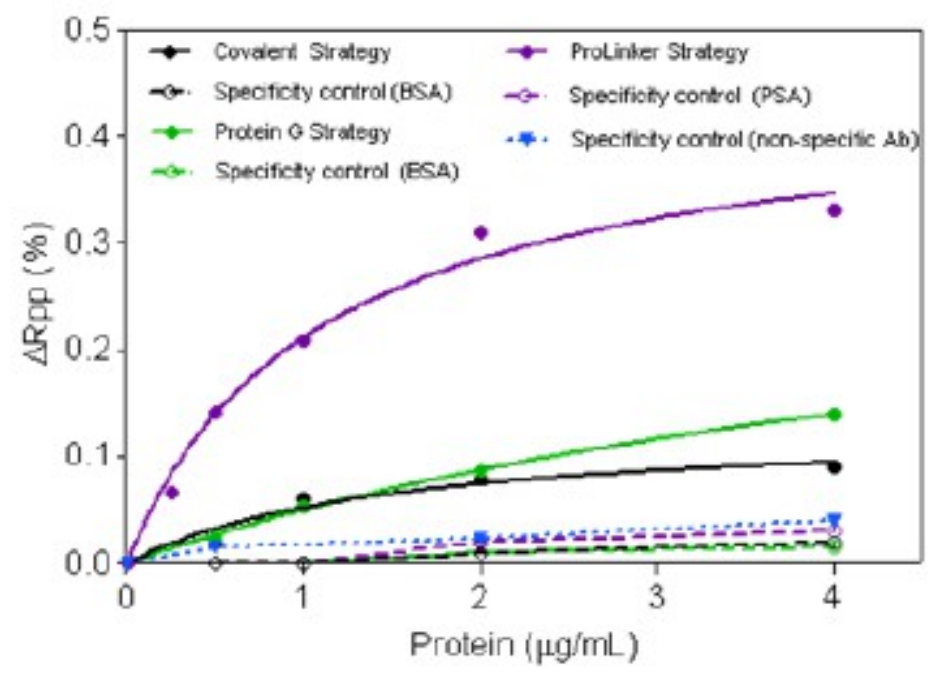


Fig. 4. (A) The SPR-signals obtained by differently modified SPRchips. (B) Equilibrium angle dependence from antibody immobilization technique: a, MUA/intact-antiHGH; b, CMD/intact-anti HGH; c, MUA/ pG/intact-anti-HGH; d, Au/frag-anti-HGH. The HGH concentration in all tested samples was the same: 1.59 $\mu$ M. Reprinted from [6] with permission from Royal Chemical Society).

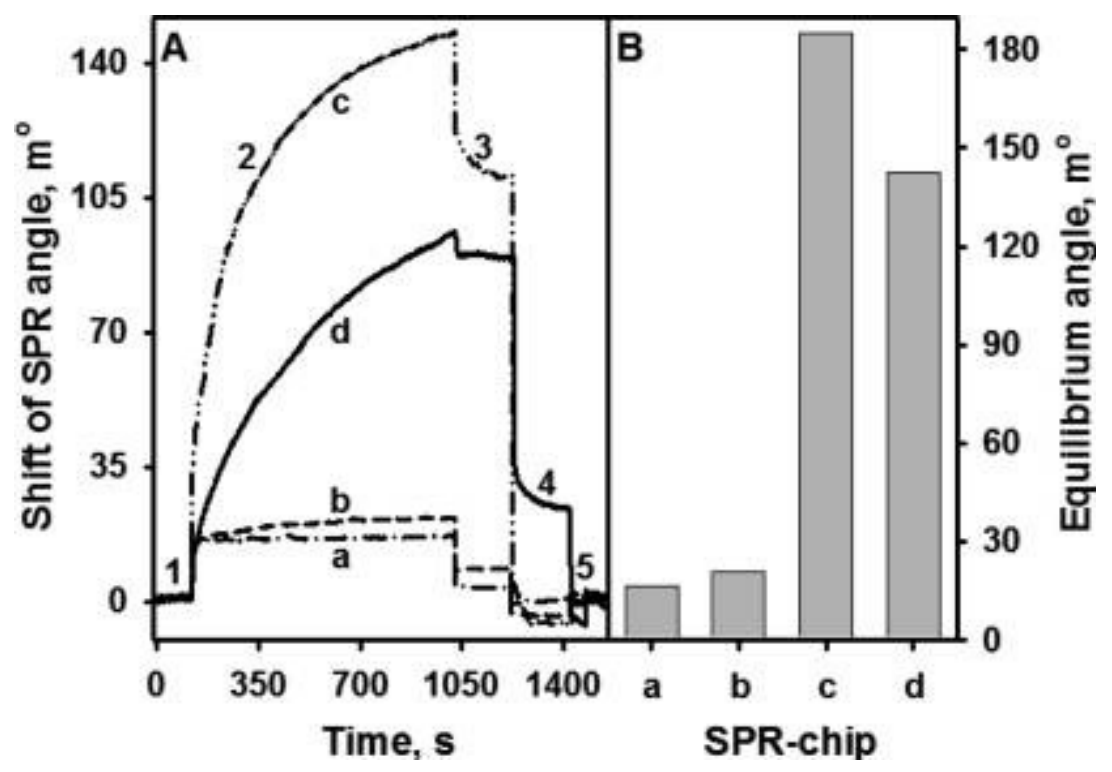


Table 1. Comparison of the analytical performance of random and oriented immobilization strategies

\begin{tabular}{|c|c|c|c|c|c|c|c|c|}
\hline & \multicolumn{8}{|c|}{ Immobilization strategy } \\
\hline $\begin{array}{l}\text { Analytical } \\
\text { application }\end{array}$ & Adsorption & Covalent & $\begin{array}{l}\text { Protein A, } \\
\text { G binding }\end{array}$ & $\begin{array}{l}\text { Avidin- } \\
\text { biotin }\end{array}$ & $\begin{array}{l}\text { Polymer } \\
\text { supports }\end{array}$ & $\begin{array}{l}\text { Fragment } \\
\text { ed } \\
\text { antibodie } \\
\mathrm{s}\end{array}$ & $\begin{array}{l}\text { Gold-coated } \\
\text { Nanosurface }\end{array}$ & Ref. \\
\hline $\begin{array}{l}\text { Enumeration of } \\
\text { bacteria }\end{array}$ & $\begin{array}{l}\text { Non- } \\
\text { specific }\end{array}$ & SAM & & $\begin{array}{l}\text { Specific } \\
\text { adsorption }\end{array}$ & & & $\begin{array}{l}\text { Au magnetic } \\
\text { NPs: } \\
\uparrow \text { sensitive } \\
\uparrow \text { rapid }\end{array}$ & [9] \\
\hline $\begin{array}{l}\text { Anti- human } \\
\text { Fetuin A antibody }\end{array}$ & $\begin{array}{l}\text { Sylane } \\
\text { functionaliz } \\
\text { ed gold }\end{array}$ & $\begin{array}{l}\text {-Sylane + } \\
\text { NHS/EDC } \\
\text { activated gold } \\
\text {-Dextran: } \uparrow \boldsymbol{A b} \\
\text { density }\end{array}$ & $\begin{array}{l}- \text {-Passive } \\
\text { adsorption } \\
\text { Protein A } \\
\text {-Covalent } \\
\text { Protein A: } \\
\uparrow \text { sensitiv } \\
\text { e }\end{array}$ & & & & & {$[24]$} \\
\hline $\begin{array}{l}\text { Characterization of } \\
\text { multiwalled } \\
\text { carbon nanotubes } \\
\text { assemby (Anti- } \\
\text { goat IgG) }\end{array}$ & & $\begin{array}{l}\text { Thiol SAM+ } \\
\text { carbon } \\
\text { nanotubes: } \\
\text {-covalent (NHS): } \\
\uparrow \text { sensitive, } \\
\uparrow \text { specific }\end{array}$ & & & & & $\begin{array}{l}\text { Thiol SAM+ } \\
\text { carbon } \\
\text { nanotubes: } \\
\text {-direct } \\
\text {-PBSE } \\
\text { attachment }\end{array}$ & {$[10]$} \\
\hline $\begin{array}{l}\text { Surface } \\
\text { Characterization } \\
\text { (IgG) }\end{array}$ & & $\begin{array}{l}\text {-SAM-MHDA: } \uparrow \\
\text { availability, } \uparrow \\
\text { signal to noise } \\
\text { ratio } \\
\text {-Dextran hydrogel } \\
\text { matrix (CM5, C1 } \\
\text { chips) }\end{array}$ & & $\begin{array}{l}\text {-SAM- } \\
\text { MHDA }\end{array}$ & & & & {$[22]$} \\
\hline $\begin{array}{l}\text { Detection of food } \\
\text { pathogen in milk }\end{array}$ & & $\begin{array}{l}\text {-Thiol SAM EG: } \\
\uparrow \text { sensitive, } \\
\uparrow \text { non-specific }\end{array}$ & & & $\begin{array}{l}\text {-OEG } \\
\text { methacrylat } \\
\mathrm{e} \approx \text { fouling }\end{array}$ & & & {$[23]$} \\
\hline
\end{tabular}




\begin{tabular}{|c|c|c|c|c|c|c|c|c|}
\hline & & $\begin{array}{l}\text { response } \\
\text {-Thiol SAM } \\
\text { hydroxyl- } \\
\text { carboxy-: } \uparrow \uparrow \text { non- } \\
\text { specific } \\
\text { response }\end{array}$ & & & $\begin{array}{l}\text { thiol SAM } \\
\text {-PolyHEMA } \\
\text { brushes: } \\
\uparrow \text { non- } \\
\text { fouling in } \\
\text { milk }\end{array}$ & & & \\
\hline $\begin{array}{l}\text { Human growth } \\
\text { hormone (anti- } \\
\text { HGH) } \\
\text { Comparative study }\end{array}$ & & $\begin{array}{l}\text {-Thiol SAM } \\
\text {-Dextran } \\
\text { hydrogel: } \\
\uparrow \text { coverage }\end{array}$ & $\begin{array}{l}\text { SAM+Prot } \\
\text { G: } \\
\uparrow \text { antigen } \\
\text { binding }\end{array}$ & & & $\begin{array}{l}\text { Frag-anti- } \\
\text { HGH thiol } \\
\text { groups: } \\
\uparrow \text { efficien } \\
\quad \boldsymbol{t}\end{array}$ & & [6] \\
\hline $\begin{array}{l}\text { IL-6 on human } \\
\text { fibroblast cells } \\
\text { (sandwich assay) }\end{array}$ & & $\begin{array}{l}\text { Mixed SAM: } \uparrow \boldsymbol{A b} \\
\text { binding } \\
\text { capacity (direct } \\
\text { method) }\end{array}$ & $\begin{array}{l}\text { Mixed SAM } \\
+ \text { ProtG: } \uparrow \\
\text { non- } \\
\text { specific } \\
\text { binding } \\
\text { (indirect) } \\
\end{array}$ & & & & & {$[25]$} \\
\hline $\begin{array}{l}\text { Determination of } \\
\text { bovine leukemia } \\
\text { virus (BLV) }\end{array}$ & $\begin{array}{l}\text { Random } \\
\text { adsorption } \\
\text { native } A b\end{array}$ & $\begin{array}{l}\text { SAM: Random } \\
\text { covalent native } \\
\text { Ab: } \downarrow \text { suitable }\end{array}$ & & & & $\begin{array}{l}\text { Oriented } \\
\text { frag-Ab: } \\
\uparrow \text { sensiti } \\
\text { ve }\end{array}$ & & {$[58]$} \\
\hline $\begin{array}{l}\text { Staphylococcal } \\
\text { enterotoxin B }\end{array}$ & & & & & & $\begin{array}{l}-\mathrm{NH}_{2} \\
- \text { Thiol: } \\
\uparrow \text { bindin } \\
\mathbf{g} \\
\text { capacity }\end{array}$ & & [59] \\
\hline $\begin{array}{l}\text { Salmonella } \\
\text { detection (IgG,Fc } \\
\text { region) }\end{array}$ & & $\begin{array}{l}\text { GBP-Protein A } \\
\text { (gold binding } \\
\text { petide fused to } \\
\text { Protein A): direct } \\
\text { immobilization }\end{array}$ & & & & & $\begin{array}{l}\text { Au NP +GBP- } \\
\text { Protein A: } \\
\uparrow \text { signal } \\
\uparrow \text { sensitivity }\end{array}$ & [31] \\
\hline $\begin{array}{l}\text { Single domain Abs } \\
\text { (SdAb) fusion } \\
\text { constructs }\end{array}$ & & $\begin{array}{l}\text { Randomly Direct } \\
\text { attachment: } \\
\downarrow \text { signal } \\
\downarrow \text { sensitive }\end{array}$ & & $\begin{array}{l}\text { sdAb- } \\
\text { strept: } \\
\uparrow \text { surface } \\
\text { density }\end{array}$ & & & & {$[38]$} \\
\hline
\end{tabular}




\begin{tabular}{|c|c|c|c|c|c|}
\hline $\begin{array}{l}\text { Gliadin detection } \\
\text { (amperometric } \\
\text { detection SPR } \\
\text { characterization) }\end{array}$ & & & & $\begin{array}{l}\text {-whole - } \\
\text { SH Ab } \\
\text {-Fab frag: } \\
\uparrow \text { stable }\end{array}$ & [59] \\
\hline $\begin{array}{l}\text { Carcinoembryonic } \\
\text { antigen detection } \\
\text { (CEA) }\end{array}$ & $\begin{array}{l}\text {-SAM } \\
\text { thiol: } \downarrow \text { signal } \\
\text {-SAM mixed } \\
\text { thiol+OEG and } \\
\text { Dextran } \\
\text { antigen } \\
\text { detection }\end{array}$ & $\begin{array}{l}\text { - SAM + } \\
\text { Protein A } \\
\text { and G: } \\
\uparrow \text { signal }\end{array}$ & & & [13] \\
\hline $\begin{array}{l}\text { Characterization } \\
\text { of } \mathrm{Ab} \text { orientation }\end{array}$ & & $\begin{array}{c}\text { Protein G } \\
\approx \text { density } \\
\mathbf{A b} \\
\text { activity }\end{array}$ & $\begin{array}{l}\text { Calixarene } \\
\text { SAM } \approx \\
\text { density } \\
\text { and } \mathbf{A b} \\
\text { activity }\end{array}$ & & [52] \\
\hline
\end{tabular}

NPs: nanoparticles; Ab: antibody PBSE: 1 pyrenebutanoic acid succinimidyl ester; MHDA: 16 mercaptohexadecanoic acid; EGhexa ethylene glycol undecanethiol; Strept: streptavidin; frag.: fragment. Source: Antibody immobilization SPR (ISI WEB of Knowledge) 
Elba Mauriz

Instituto de Ciencia y

Tecnología de los Alimentos (ICTAL)

University of León,

24071 León Spain

Phone: +34 987293071

Fax: +34 987293073

e-mail: elba.mauriz@unileon.es
TrAC Trends in Analytical Chemistry

León, 31 ${ }^{\text {st }}$ October 2015.

Dear Editor,

Please find enclosed our manuscript entitled 'Towards the design of universal immunosurfaces for SPR-based assays: a review', that we wish to submit for publication in TrAC Trends in Analytical Chemistry.

This work reviews recent advances of SPR immobilization strategies for immunoanalytical formats. In particular, we concentrate on the current trends based on the combination of traditional and novel biotechnological alternatives, like fusion proteins, polymer brushes and intact-fragmented antibodies, recently developed for the design of universal interfaces. Special attention has been paid to the functionalization of SPR biosensor surfaces with major applications in clinical diagnostics and real-time analysis.

In comparison with previous reviews this work provides additional and relevant results on the the search for versatile and reliable immobilization protocols. Our approach may also be useful in designing chemically modified biosurfaces for the construction of high feasible bioreceptor layers. Therefore, we think that our contribution is in the scope of your journal.

Yours sincerely,

Elba Mauriz, Ph.D. 
- The value of selecting the appropriate immobilization method for measuring antigen-antibody interactions.

- Recent advances of SPR immobilization strategies for immunoanalytical formats.

- Current trends based on the combination of traditional and novel biotechnological alternatives.

- Functionalization of SPR biosensor surfaces with major applications in clinical diagnostics and real-time analysis. 
Dear Editor,

I am writing to you regarding the referees' comments to the manuscript entitled 'Towards the design of universal immunosurfaces for SPR-based assays: a review'. We sincerely apreciate the comments. In response to the queries, we have revised the manuscript paying special attention to the referees' requests.

We hope that the revised version can fulfil the requirements for publication in your journal.

Sincerely yours,

Dr. Elba Mauriz

\section{Referee's comments}

The submitted manuscript reviews the recent progress regarding surface biofunctionalization techniques applied to SPR biosensors. The contribution discusses about a wide range of proposed strategies to increase the biosensor performance, to control the stability and antibody orientation, and also discuss the possibility of a universal immobilization method.

In order to increase the knowledge of the surface biofunctionalization strategies and SPR biosensors, this paper has an appropriate approach suitable for this journal. Likewise, the submitted paper shows a good literature review and it is well written. Therefore, I recommend its acceptance. However,

I would like to comment some details to the authors in order to improve the contribution:

1. Abstract. The authors say: "Surface biofunctionalization..., is an essential step to provide reliable detection of biomolecular binding events monitored by Surface Plasmon Resonance (SPR), ...". Of course this statement is true, but I consider that a successful surface biofunctionalization is crucial for all the biosensor techniques, not only SPR.

Response: We agree with the referee's comment. As he/she mentiones surface biofunctionalization is essential for all types of biosensor devices. Following the referee's suggestion, we have modified the sentence and we have added 'and other biosensor techniques' to the sentence.

2. Introduction, $3^{\text {rd }}$ paragraph. From this paragraph I understand that $1 \mathrm{KDa}$ is the limit of sensitivity of the technique. Is that correct?

Response: The level of sensitivity of $1 \mathrm{KDa}$ applies only when SPR employs direct detection formats for the monitoring of binding events. However, lower limits of detection for molecules below $1 \mathrm{KDa}$ have been broadly achieved by using binding inhibition assays involving the antigen immobilization.

3. Figure 1. The figure is not complete in the submitted version (the bottom left part is missing).

Response: We are sorry for the error. We have corrected it in the revised version. 
4. Table 1. I do not understand the comparison of the analytical performance. Which application is the most sensitive, the fastest?

Response: The purpose of the Table is to report the application of different immobilization methods for the detection of the same analyte by comparing several analytical parameters. Since results depend on the specific characteristics of the target analyte it is difficult to extract general conclusions from the data compared. However, it is possible to consider that antibody oriented formats provide better sensitivity and selectivity values, while polymer supports increase biosurfaces densities. In order to improve the understanding of these aspects, the following sentences have been added to the last paragraph of section 2.2.: 'As shown in Table 1, better sensitivity and selectivity values are obtained for SAMs involving oriented immobilization formats and non-fouling biosurface designs. The combined use of oriented and non-fouling surfaces may enhance both antibody binding capacity and availability'.

5. Reference 53 is not correctly written.

Response: Reference 53 has been corrected.

6. Conclusions, 2nd paragraph. The authors say: "Investigation on the subject suggests significant benefits of oriented immobilization formats for improving assay selectivity". From the Section 2.3 I understood that the oriented immobilization improves the sensitivity, instead of the selectivity.

Response: We think that the referee's observation is in line with the discussed statement since the specificity provided by well-ordered antibody oriented surfaces also causes the improvement of the assay sensitivity. In particular, our sentence refers to the use of non-fouling surfaces that avoid the undesired adsorption of nonspecific biomolecules. 